\title{
O cumprimento da medida socioeducativa de internação no Brasil: uma revisão sistemática da literatura
}

\author{
Vinicius Coscioni \\ Universidade Federal do Espirito Santo \\ Luiza Lins Araújo Costa \\ Universidade Federal de Sergipe \\ Edinete Maria Rosa \\ Universidade Federal do Espirito Santo \\ Sílvia Helena Koller \\ Universidade Federal do Rio Grande do Sul
}

\begin{abstract}
Resumo
O objetivo deste estudo é identificar as contribuições de pesquisas empíricas publicadas em periódicos científicos sobre a caracterização do processo de cumprimento da medida socioeducativa de internação no Brasil. Trata-se de uma revisão sistemática da literatura que analisou 30 trabalhos, cujos resultados foram tratados a partir da análise temática. Observou-se a precarização da estrutura física e das atividades ofertadas, bem como um clima organizacional coercitivo marcado por relações interpessoais hostis, o que resulta na perda da identidade pessoal, sofrimento, reincidência e preconceito na comunidade. Elementos positivos foram também destacados, referentes à adequação da estrutura física e das atividades desenvolvidas, a um clima organizacional livre de violência e à vinculação dos adolescentes com seus familiares e funcionários, o que favorece a aprendizagem e proteção. A revisão identificou a prevalência de práticas coercitivas sobre as pedagógicas e ressaltou a necessidade de pesquisas que investiguem os processos decorrentes da privação de liberdade.
\end{abstract}

Palavras-chave: Medidas Socioeducativas; Adolescente em Conflito com a Lei; Revisão de Literatura; Direitos Humanos.

\section{The undergoing of the socio-educational measures of confinement in Brazil: a systematic review of the literature}

\begin{abstract}
This paper aims to identify the contributions of empirical researches published in scientific journals on the characterization of the process of undergoing of socio-educational measures of confinement in Brazil. It is a systematic review of the literature that analyzed 30 papers, whose results were treated by thematic analysis. It was observed the precariousness of physical structure and leisure activities, as well as a coercive organizational climate marked by hostile interpersonal relationships, resulting in the loss of personal identity, suffering, recidivism, and prejudice in community. Positive elements were also highlighted, regarding the adequacy of physical structure and developed activities, to an organizational climate free of violence, and to the bonding of adolescents to their families and workers, which favors learning and protection. The review identifies a prevalence of coercive practices over pedagogical ones, and the need of studies to investigate processes arising from deprivation of liberty.
\end{abstract}

Keywords: Socio-Educational Measures; Adolescents in Conflict with the Law; Literature Review; Human Rights.

\section{El cumplimiento de la medida socioeducativa de internamiento en Brasil: una revisión sistemática de la literatura}

\begin{abstract}
Resumen
El objetivo de este estudio es identificar la contribución de investigaciones empíricas publicadas en revistas científicas sobre la caracterización del proceso de cumplimiento de medida socioeducativa de internamiento en Brasil. Se trata de una revisión sistemática de la literatura que analizó 30 estudios, cuyos resultados se trataron a partir del análisis temático. Se observó la precariedad de la estructura física y actividades ofrecidas, así como un clima organizacional coercitivo, marcado por relaciones interpersonales hostiles, lo que resulta en pérdida de identidad personal, sufrimiento, reincidencia y prejuicio en la comunidad. Elementos positivos también se pusieron de relieve, en cuanto a la adecuación de la estructura física y las actividades desarrolladas, a un clima organizacional libre de violencia y a la vinculación de los adolescentes con sus familias y empleados, lo que favorece el aprendizaje y la protección. La revisión identificó la prevalencia de prácticas coercitivas sobre las pedagógicas, y subrayó la necesidad de estudios que investiguen los procesos derivados de privación de libertad.
\end{abstract}

Palabras clave: Medidas Socioeducativas; Adolescente en Conflicto con la Ley; Revisión de Literatura; Derechos Humanos. 
O objetivo do presente estudo é identificar as contribuições de pesquisas empíricas publicadas em periódicos científicos sobre a caracterização do processo de cumprimento da medida socioeducativa (MSE) de internação no Brasil. Esta MSE é descrita pelo Estatuto da Criança e do Adolescente (ECRIAD) (Brasil, 1990) como "medida privativa da liberdade, sujeita aos princípios de brevidade, excepcionalidade e respeito à condição peculiar de pessoa em desenvolvimento" (Art. n. 121). Ao compreender que investigações científicas lançam luz sobre a realidade, considerase que uma revisão sistemática da literatura sobre o tema possa contribuir para o trabalho de profissionais e estudiosos da área.

Segundo o ECRIAD (Brasil, 1990), adolescentes são sujeitos de direito e em condição peculiar do desenvolvimento, sendo penalmente inimputáveis quando do cometimento de atos infracionais. Portanto, adolescentes entre 12 e 18 anos incompletos respondem por seus atos ilícitos por meio do cumprimento de MSE orientadas pelo Sistema Nacional de Atendimento Socioeducativo (SINASE) - instituído pela Lei Federal no 12.594 (Brasil, 2012), e subsidiado por uma resolução anterior (Brasil, 2006).

Apesar de o SINASE (Brasil, 2006) observar que o cumprimento da MSE possui uma natureza sancionatória, fica claramente expresso que a natureza sociopedagógica deve prevalecer sobre a primeira. $\mathrm{O}$ atendimento socioeducativo deve funcionar idealmente como fator de proteção, reduzindo os fatores de risco advindos de situações pregressas de vulnerabilidade e otimizando aspectos positivos em direção a um desenvolvimento saudável. Esta proposta de ação socioeducativa é embasada pela Doutrina da Proteção Integral, que se tornou mais evidente com a promulgação do ECRIAD, em 1990. A compreensão dos adolescentes como sujeitos de direitos e em situação peculiar do desenvolvimento rompeu com as práticas higienistas que caracterizavam a legislação infantojuvenil anterior ao ECRIAD. Embasado pela Doutrina da Situação Irregular, o Código de Menores previa sumariamente um conjunto de medidas privativas de liberdade, que se preocupavam muito pouco com o desenvolvimento de seus atendidos (Rizzini \& Pilotti, 2011).

Não obstante as mudanças legislativas, um caráter sancionatório tem se mantido presente no atendimento a adolescentes em cumprimento de MSE. Um relatório produzido pelo Conselho Federal da Ordem dos Advogados e Conselho Federal de Psicologia (2006), a partir de visitas realizadas a unidades socioeducativas de 21 estados e Distrito Federal, revelou um contexto de violação de direitos. Frequentes relatos de uso de métodos coercitivos parecem caracterizar o período de cumprimento da MSE. Para além deste relatório, o sistema socioeducativo tem sido objeto de análise de pesquisas conduzidas no Brasil em diversas áreas do conhecimento e são essas as pesquisas que o presente estudo se propõe a investigar.

\section{Método}

Este artigo configura-se como uma revisão sistemática da literatura, tendo-se consultado as bases de dados SciELO, LILACS, PePSIC e Index Psi, que tradicionalmente indexam produções científicas brasileiras. Estabeleceu-se como recorte temporal os trabalhos publicados a partir de 1990, data de promulgação do ECRIAD, tendo-se encontrado, contudo, somente referências publicadas a partir de 1992.

Buscaram-se trabalhos que apresentassem o adjetivo 'socioeducativo' em seu resumo a partir da estratégia "socioeducativo OR sócio-educativo [resumo]". Optou-se por empregar uma estratégia de busca ampla, tendo em vista que, embora vários termos sejam utilizados para se referir às MSE, o adjetivo socioeducativo aparece como elemento comum. A busca foi realizada no dia 17 de outubro de 2015, tendo-se encontrado: 206 trabalhos no SciELO, 213 no LILACS, 51 no PePSIC e 103 no Index Psi, somandose 338 referências, se controladas as duplicações. Foram excluídos os estudos teóricos produzidos em outros países e estudos empíricos que se referiam a outras realidades que não a brasileira, restando 256 trabalhos. Desses, foram excluídos os que abordavam outros assuntos, que não adolescência em conflito com a lei, restando 172 manuscritos. A partir da leitura dos resumos dos trabalhos restantes, selecionaram-se apenas aqueles que traziam informações que caracterizavam o cumprimento da MSE de internação, resultando 43 referências. Optou-se por analisar apenas os artigos científicos empíricos, de modo a se eliminar 11 referências que se configuravam como artigos teóricos, relatos de experiências ou que foram publicadas em outros veículos de divulgação. Sete referências foram descartadas após a leitura: seis por se relacionarem ao período de internação provisória ou a outras MSE; e uma por se perceber que dois artigos de nomes diferentes discutiam os mesmos dados. Com as exclusões, restaram 25 trabalhos.

As referências dos trabalhos selecionados foram analisadas, buscando-se outros artigos empíricos não contemplados na busca. Os resumos de tais artigos foram avaliados, tendo-se selecionado nove trabalhos que possivelmente contribuiriam para a pesquisa. Desses, 
quatro foram descartados: um por ser estudo teórico, um por se referir a MSE em meio aberto e outros dois por não trazerem informações sobre o cumprimento da MSE de internação. Ao final, 30 manuscritos foram selecionados para compor a revisão. Todo o processo de seleção das referências foi realizado por dois juízes, tratando-se as diferenças por meio do consenso.

As pesquisas foram inicialmente caracterizadas quanto a seu: periódico de publicação; embasamento teórico; objetivos; delineamento; local, fontes e métodos de coleta dos dados; e a presença, ou ausência, da descrição dos procedimentos de coleta e análise dos dados. Essas informações foram tabeladas, buscando-se padrões que pudessem organizar os estudos.

Os resultados das pesquisas foram tratados a partir da Análise Temática (Braun \& Clark, 2006) com o auxílio do software NVivo 10. Inicialmente, foi realizada uma leitura flutuante do corpus de análise, familiarizando-se com o conteúdo dos manuscritos. Em um segundo momento, foram codificados os trechos dos artigos que poderiam contribuir para o objetivo do trabalho. Esses dados codificados foram reunidos por similaridade semântica e, devidamente agrupados, iniciou-se o processo de categorização, propondose núcleos de sentido que os explicassem. Temas e categorias foram então propostos, retomando os dados codificados no sentido de verificar se as unidades temáticas saturavam as informações presentes nos artigos. A análise foi então refeita, tendo-se codificado e agrupado os dados a partir da categorização proposta. Os procedimentos de coleta dos dados a partir da leitura dos artigos, bem como de criação das categorias foram realizadoa por dois juízes trabalhando conjuntamente, sendo os procedimentos seguintes realizados apenas por um desses juízes.

\section{Resultados e Discussão}

As pesquisas foram classificadas conforme o periódico e ano de publicação e local de realização, sendo os resultados sumarizados na Tabela 1. Os trabalhos foram publicados entre 1999 e 2015, sendo 18 deles $(60 \%)$ publicados entre 2011 e 2015 , nove $(30 \%)$ entre 2006 e 2010 e três (10\%) antes de 2006. A maioria foi publicada em periódicos da área da Psicologia $(n=18,60 \%)$, seguidos dos periódicos da área da Saúde $(n=5,17 \%)$, Serviço Social $(n=2,7 \%)$, Área Interdisciplinar $(n=2,7 \%)$, Terapia Ocupacional $(n=1$, $3 \%)$, Ciências Sociais $(n=1,3 \%)$ e Educação $(n=1$, $3 \%$ ). Houve predominância de trabalhos produzidos no Sudeste $(n=10,33 \%)$, seguido das regiões Sul $(n=7$, $23 \%)$, Nordeste $(n=6,20 \%)$ e Centro-Oeste $(n=5$, $17 \%)$; nenhum trabalho incluído na amostra final foi produzido na região Norte. A maior parte dos artigos referiram-se a unidades de internação localizadas em regiões metropolitanas $(n=16,53 \%)$, havendo oito trabalhos $(27 \%)$ relacionados a unidades situadas no interior e outros quatro trabalhos $(13 \%)$ comparando unidades de regiões metropolitanas com unidades do interior. Dois manuscritos (7\%) não especificaram o local de realização da pesquisa. A comparação dos trabalhos por similaridade teórico-metodológica gerou cinco agrupamentos, descritos a seguir.

Um primeiro grupo é composto por dez trabalhos (33\%) que se embasaram em teorias da Psicologia do Desenvolvimento, tais como a Psicologia da Moralidade (Monte \& Sampaio, 2012; Salgado \& Alencar, 2012), a Perspectiva Sistêmica (Souza \& Costa, 2012a, 2012b \& 2013), a Teoria das Redes de Significações (Souza \& Menezes-Santos, 2010) e estudos sobre fatores de risco e de proteção (Branco \& Wagner, 2009; Branco, Wagner, \& Demarchi, 2008; Muller, Barboza, Oliveira, Santos, \& Paludo, 2009; Silva, Ruzzi-Pereira, \& Pereira, 2013). As pesquisas adotaram diferentes delineamentos, como o estudo de múltiplos casos, a pesquisa narrativa e o método clínico. Houve prevalência do uso da entrevista com adolescentes, bem como com funcionários e familiares, sendo também utilizados diários de campo e prontuários como fontes de dados. Os trabalhos trouxeram detalhamentos sobre os procedimentos de análise dos dados, que recorrentemente utilizaram a análise de conteúdo como técnica de tratamento de informações.

De um segundo grupo fazem parte nove relatos (30\%) embasados por diferentes teorias da Psicologia Social e Sociologia, a saber: a Teoria das Representações Sociais (Aranzedo \& Souza, 2007; Coutinho, Estevam, Araújo, \& Araújo, 2011; Estevam, Coutinho, \& Araújo, 2009; Galvão, Costa, \& Camino, 2005; Lima, 2006), a Abordagem Sócio-Histórica (Padovani \& Ristum, 2013; Silva \& Ristum, 2010), a Teoria Marxista (Medeiros \& Paiva, 2015) e teorias sociológicas sobre o lazer (Lazaretti-da-Conceição \& Cammarosano-Onofre, 2013). De abordagem qualitativa ou mista, o método de coleta de dados mais utilizado foi a entrevista, tendo um trabalho utilizado questionário. Diário de campo e recortes de jornais foram utilizados como instrumentos complementares às entrevistas. A análise de conteúdo foi a técnica de tratamento de dados mais mencionada, ainda que frequentemente não fossem explicitados os procedimentos adotados para conduzir a análise.

Um terceiro grupo é formado por cinco artigos (17\%) que apresentavam como embasamento do trabalho o estudo das legislações e políticas públicas socioeducativas (Ferrão, Zappe, \& Dias, 2012; 
TABELA 1

Autores, ano e periódico de publicação, área do conhecimento e cidade de realização das pesquisas que compõem o corpus de análise.

\begin{tabular}{|c|c|c|c|}
\hline Autor(es) e Ano & Periódico de Públicação & Área de Conhecimento & Cidade \\
\hline Aragão, Margotto, \& Batista, 2012 & EPOS & Saúde & Grande Vitória, ES \\
\hline Aranzedo \& Souza, 2007 & $\begin{array}{l}\text { Revista Electrónica de Psicología } \\
\text { Política }\end{array}$ & Psicologia & Grande Vitória, ES \\
\hline Branco \& Wagner, 2009 & Ciência \& Saúde Coletiva & Saúde & Porto Alegre, RS \\
\hline Branco, Wagner, \& Demarchi, 2008 & Psicologia: Reflexão e Crítica & Psicologia & Porto Alegre, RS \\
\hline Castro \& Guareschi, 2008 & Psicologia \& Sociedade & Psicologia & Porto Alegre, RS \\
\hline $\begin{array}{l}\text { Coutinho, Estevam, Araújo, \& Araújo, } \\
2011\end{array}$ & Psicologia em Estudo & Psicologia & $\begin{array}{l}\text { João Pessoa e Campina } \\
\text { Grande, PB }\end{array}$ \\
\hline Dias, Arpini, \& Simon, 2011 & Psicologia \& Sociedade & Psicologia & Santa Maria, RS \\
\hline Estevam, Coutinho, \& Araújo, 2009 & Psico & Psicologia & $\begin{array}{l}\text { João Pessoa e Campina } \\
\text { Grande, PB }\end{array}$ \\
\hline Ferrão, Zappe, \& Dias, 2012 & Barbarói & Interdisciplinar & Santa Maria, RS \\
\hline Galvão, Costa, \& Camino, 2005 & Psico & Psicologia & $\begin{array}{l}\text { João Pessoa e uma cidade do } \\
\text { interior não especificada, } \mathrm{PB}\end{array}$ \\
\hline $\begin{array}{l}\text { Lazaretti-da-Conceição \& } \\
\text { Cammarosano-Onofre, } 2013\end{array}$ & $\begin{array}{l}\text { Revista Latinoamericana de } \\
\text { Ciencias Sociales, Niñez y Juventud }\end{array}$ & Ciências Sociais & Vale do Paraíba, SP \\
\hline Lima, 2006 & Psicologia \& Sociedade & Psicologia & São Paulo, SP \\
\hline Malvasi, 2011 & Saúde e Sociedade & Saúde & São Paulo, SP \\
\hline Medeiros \& Paiva, 2015 & Estudos e Pesquisas em Psicologia & Psicologia & Caicó e Mossoró, RN \\
\hline Menicucci \& Carneiro, 2011 & Serviço Social \& Sociedade & Serviço Social & $\begin{array}{l}\text { Sete Lagoas e Belo } \\
\text { Horizonte, MG }\end{array}$ \\
\hline Monte \& Sampaio, 2012 & Psicologia: Reflexão e Crítica & Psicologia & Interior, PE \\
\hline $\begin{array}{l}\text { Muller, Barboza, Oliveira, Santos, \& } \\
\text { Paludo, } 2009\end{array}$ & $\begin{array}{l}\text { Revista Brasileira Adolescência e } \\
\text { Conflitualidade }\end{array}$ & Interdisciplinar & Interior, RS \\
\hline Oliveira \& Assis, 1999 & Cadernos de Saúde Pública & Saúde & Rio de Janeiro, RJ \\
\hline Oliveira, 2003 & Katálysis & Serviço Social & Rio de Janeiro, RJ \\
\hline Padovani \& Ristum, 2013 & Educação e Pesquisa & Educação & não menciona \\
\hline Salgado \& Alencar, 2012 & Psicologia Argumento & Psicologia & Grande Vitória, ES \\
\hline $\begin{array}{l}\text { Scisleski, Bruno, Galeano, Santos, \& } \\
\text { Silva, } 2015\end{array}$ & Psicologia \& Sociedade & Psicologia & Campo Grande, MS \\
\hline Silva \& Ristum, 2010 & Psicologia: Ciência e Profissão & Psicologia & não menciona \\
\hline Silva, Ruzzi-Pereira, \& Pereira, 2013 & $\begin{array}{l}\text { Caderno de Terapia Ocupacional } \\
\text { da UFSCar }\end{array}$ & Terapia Ocupacional & Triângulo Mineiro, MG \\
\hline Souza \& Costa, 2012a & Revista Psicologia Política & Psicologia & Planaltina, DF \\
\hline Souza \& Costa, 2012b & Acta Colombiana de Psicología & Psicologia & Planaltina, DF \\
\hline Souza \& Costa, 2013 & Psico-USF & Psicologia & Planaltina, DF \\
\hline Souza \& Menezes-Santos, 2010 & Pesquisas e Práticas Psicossociais & Psicologia & Maceió, AL \\
\hline Vilarins, 2014 & Ciência \& Saúde Coletiva & Saúde & Brasília, DF \\
\hline Zappe \& Dias, 2011 & Psico & Psicologia & Santa Maria, RS \\
\hline
\end{tabular}

Tabela criada a partir dos dados dos manuscritos que compõe o corpus de análises.

Menicucci \& Carneiro, 2011; Oliveira, 2003; Oliveira \& Assis, 1999; Vilarins, 2014). Foram realizados levantamentos, com funcionários e adolescentes, ou pesquisas de perspectiva qualitativa, que se valiam de entrevistas, documentos e diário de campo como fontes de dados.
Quatro manuscritos (17\%) compõem um quarto grupo, que se embasou em teorias da Psicologia Institucional - a saber: a Teoria do Poder (Castro \& Guareschi, 2008; Malvasi, 2011; Scisleski, Bruno, Galeano, Santos, \& Silva, 2015) e a Esquizoanálise (Aragão, Margotto, \& Batista, 2012) - desde a 
formulação do problema de pesquisa, à delimitação do método e análise dos resultados. Esses trabalhos adotaram uma perspectiva qualitativa, como cartografia, pesquisa narrativa, pesquisa-intervenção ou etnografia. A entrevista com adolescentes e funcionários, diários de campo e prontuários e processos judiciais foram utilizados como fontes de dados. Esses trabalhos caracterizaram-se ainda por uma falta de clareza metodológica, não havendo descrição dos procedimentos ou técnicas de análise utilizados para chegar aos resultados.

Dois manuscritos $(7 \%)$ utilizaram a Psicanálise como base teórica e compõem, assim, o quinto grupo de trabalhos. Tratam-se de uma pesquisa documental (Zappe \& Dias, 2011) e um estudo fenomenológico (Dias, Arpini, \& Simon, 2011) conduzido por meio de entrevistas com familiares.

Com relação aos resultados dos estudos, a análise temática gerou quatro núcleos temáticos: aspectos contextuais; serviços ofertados; aspectos interpessoais; e efeitos e consequências, que serão descritos a seguir:

\section{Aspectos Contextuais}

Compõem este tema os resultados das pesquisas que caracterizavam o contexto que sedia o cumprimento da MSE. Compreende-se como contexto tanto o ambiente físico imediato, quanto elementos doutrinários e legais que influenciam o clima organizacional.

Os trabalhos, em geral $(n=16,53 \%)$, descreveram as estruturas físicas e condições infraestruturais das unidades pesquisadas como precárias e inadequadas conforme o estabelecido pela Doutrina da Proteção Integral. Os locais foram recorrentemente caracterizados como superlotados e desfavoráveis ao desenvolvimento pelas condições insatisfatórias e desumanas de higiene, alimentação, salubridade e integridade física. A comparação com presídios foi frequente, devido à prevalência de espaços fechados, muros altos, pluralidade de portões, arames retorcidos e demais estruturas de segurança.

Houve menções $(n=2,7 \%)$, contudo, a unidades cuja estrutura física favorecia o desenvolvimento dos internos. Adolescentes entrevistados em um estudo realizado no interior do Rio Grande do Sul (RS) (Muller et al., 2009) revelaram satisfação pelo ambiente da unidade. Um estudo realizado em Minas Gerais (MG) (Menicucci \& Carneiro, 2011), que comparou a estrutura física de duas unidades distintas, encontrou diferenças entre os estabelecimentos. Nesse sentido, uma delas foi considerada mais adequada aos princípios do ECRIAD e SINASE, havendo espaços abertos e verdes, semelhantes a uma residência.

A localização da unidade foi mencionada por alguns trabalhos $(n=4,13 \%)$ como um aspecto que dificultava o convívio dos adolescentes com sua família e comunidade. Enfatizaram ainda a ausência de estabelecimentos regionalizados, de modo que muitos adolescentes cumpriam a MSE em locais distantes de seu município de origem. Uma dessas pesquisas (Menicucci \& Carneiro, 2011) descreveu o caso de uma unidade construída distante de um centro urbano, o que dificultava as saídas externas dos adolescentes. Um trabalho (Medeiros \& Paiva, 2015) relatou um fato ocorrido no Rio Grande do Norte (RN), em que uma unidade da capital foi interditada, de modo que os adolescentes passaram a ser internos em um estabelecimento no interior, a mais de quatro horas de distância de suas famílias.

O clima organizacional foi frequentemente $(n=15$, $50 \%$ ) descrito como hostil, repressivo, tenso, marcado por uma insegurança generalizada, pela banalização da violência física e psicológica entre adolescentes e funcionários, bem como por situações de conflito, fuga, rebelião, motim e homicídios. Uma pesquisa realizada no Rio de Janeiro (RJ) (Oliveira \& Assis, 1999) abordou um período marcado por intensas manifestações entre os adolescentes, no ano de 1994. O mesmo estudo descreveu uma instituição destinada a adolescentes do sexo feminino, cujas práticas cotidianas eram permeadas pelo uso explícito da violência, havendo relatos de funcionários usando até mesmo objetos de repressão para conter as internas. Um estudo de caso conduzido também no RJ (Oliveira, 2003) descreveu a história de um adolescente que, ao cumprir MSE por prática de estupro, foi alvo de violência física cometida por adolescentes e funcionários e de sevícia sexual praticada por outros internos.

Uma pesquisa realizada com quatro professores em atuação no sistema socioeducativo (Silva \& Ristum, 2004) indicou que o contexto de banalização da violência refletia em manifestações de agressividade nas escolas sediadas nas unidades. Conduzido mediante aplicação de questionários abertos, o estudo tinha por objetivo compreender a percepção dos participantes sobre o fenômeno de violência escolar. $\mathrm{O}$ trabalho revelou que recorrentemente, durante as aulas, havia manifestações explícitas e implícitas de violência entre os adolescentes, bem como destes para com os professores.

Alguns estudos $(n=7,23 \%)$ revelaram o uso excessivo de procedimentos de isolamento como sanção disciplinar. Adolescentes e uma técnica participante de uma pesquisa sediada em MG (Menicucci \& Carneiro, 2011) discordaram de tais práticas, seja por seu uso indiscriminado, seja pela inadequação de se submeter adolescentes a um método que mantém alguém isolado e ocioso. Adolescentes participantes de uma pesquisa conduzida em São Paulo (SP) (Lazaretti-da-Conceição 
\& Cammarosano-Onofre, 2013) posicionaram-se ora contra e ora a favor dessas práticas de isolamento. Os participantes que se posicionaram a favor qualificaram-nas como um espaço de reflexão, enquanto que os que se posicionaram contra, consideravam pertinente sua substituição por procedimentos de mediação por meio do diálogo.

Aspectos positivos no clima organizacional foram elencados por alguns estudos $(n=2,7 \%)$. Registros em diários de campo oriundos de uma pesquisa realizada no interior da Paraíba (PB) (Galvão et al., 2005) descreveram o ambiente como sem conflito e violência. Um estudo de orientação pós-estruturalista conduzido em uma unidade do Espírito Santo (ES) (Aragão et al., 2012) teve por objetivo buscar movimentos de potência de vida no encontro com adolescentes. O trabalho destacou que elementos positivos resistiam ao clima organizacional hostil, de modo a compreender que, submetidos a situações extremas, os adolescentes encontravam formas de manter a esperança em suas vidas.

Grande parte dos trabalhos $(n=24,80 \%)$ debateu sobre a lógica de funcionamento coercitiva que se sobrepunha à lógica pedagógica prevista pela Doutrina da Proteção Integral. Revelaram prevalência de um contexto inspirado por paradigmas legislativos antigos, carente de um projeto pedagógico, que leva ao fracasso do objetivo de supostamente ressocializar aos adolescentes. Um ambiente de violação de direitos e com forte ênfase sobre procedimentos disciplinares e de segurança acaba por diferenciar muito pouco o sistema socioeducativo do sistema penitenciário. Três estudos (Aranzedo \& Souza, 2007; Coutinho et al., 2011; Estevam et al., 2009), que examinaram as representações sociais de adolescentes participantes sobre o cumprimento da MSE, observaram que as práticas supostamente socioeducativas eram prevalentemente de caráter punitivo, havendo uma descrença no objetivo original de promover mudanças positivas em suas vidas.

Um estudo (Oliveira \& Assis, 1999) relatou o processo de descentralização político-administrativa ocorrente no RJ após a inauguração da nova política de atendimento a adolescentes autores de ato infracional. A partir de entrevistas com 11 funcionários, a pesquisa constatou que a transição entre políticas deu-se mediante conflito entre os concursados federais funcionários públicos mais antigos defensores dos princípios em vigência à época do Código de Menores - e os concursados estaduais - que gradativamente ocuparam seus cargos, refletindo os novos princípios. Um levantamento mais recente, realizado com 37 funcionários de uma unidade localizada no interior do RS (Ferrão et al., 2012) revelou que a efetivação dos princípios legais do ECRIAD permanecia ainda em curso na data da pesquisa.

Algumas pesquisas $(n=3,10 \%)$ relataram tentativas de unidades em cumprir com os objetivos pedagógicos previstos por lei. Um trabalho realizado no Distrito Federal (DF) (Souza \& Costa, 2012a) teve por objetivo apresentar aspectos institucionais presentes na execução da MSE a partir da observação participante registrada em diário de campo. O estudo verificou o cuidado da unidade em oferecer atividades pedagógicas e de convivência familiar que beneficiassem os adolescentes. Revelou, contudo, que essas tentativas eram inibidas por deficiências na execução das políticas públicas, tendo em vista que pouco investimento por parte do Estado era destinado aos programas de atendimento socioeducativo.

Uma segunda pesquisa teve por objetivo analisar as representações sociais de funcionários do sistema socioeducativo sobre um conjunto de mudanças ocorridas em um complexo localizado em SP (Lima, 2006). Essas mudanças referiam-se à inauguração de uma nova direção que proibia qualquer tipo de prática de violência cometida contra os adolescentes. As mudanças foram percebidas pelos funcionários como grandes inovações, ainda que fosse mencionada uma desesperança quanto à manutenção das mesmas na rotina institucional. Foram relatadas também manifestações de discriminação e rejeição por parte de funcionários de outras unidades. A pressão sobre a qual os funcionários se expressaram, resultou na descontinuidade da proposta, uma vez que o diretor responsável por essas mudanças foi remanejado para uma unidade de acolhimento institucional.

Parece que a forma como as lógicas socioeducativas e coercitivas se articulam, varia conforme as peculiaridades de cada programa de execução da MSE. Uma pesquisa realizada em MG (Menicucci \& Carneiro, 2011) que comparou duas unidades quanto à forma como lidavam com essas duas lógicas distintas, destacou que a política executada varia, dentre outros aspectos, conforme características do espaço físico, do perfil dos adolescentes e da visão dos implementadores sobre as políticas. Embora o estudo tenha encontrado diferenças entre as unidades, havia em ambas a prevalência da lógica coercitiva sobre a socioeducativa.

\section{Serviços Ofertados}

Referem-se a este tema os resultados das pesquisas que caracterizavam as atividades desenvolvidas nas unidades como forma de implementar o processo de cumprimento da MSE. Os serviços foram, de modo 
geral, descritos como precários, sendo alguns deles até mesmo ausentes, tais como os programas de acompanhamento de egressos.

Os atendimentos técnicos foram caracterizados por alguns trabalhos $(n=11,37 \%)$ como pontuais, recorrentemente ocupando funções burocráticas, nãopedagógicas, incongruentes com a proposta da Doutrina da Proteção Integral e desfalcados pela precarização do trabalho. Três pesquisas que analisaram documentos redigidos por técnicos socioeducativos identificaram um processo de produção da delinquência, a partir de relatos descontextualizados que individualizavam a conduta infracional do adolescente (Castro \& Guareschi, 2008; Scisleski et al., 2015) ou culpabilizavam seus familiares (Medeiros \& Paiva, 2015). Uma pesquisa de perspectiva etnográfica que acompanhou um adolescente em SP (Malvasi, 2011) identificou que o participante sentia-se vigiado pela psicóloga da instituição, que detinha a função de escrever laudos psicológicos para a reavaliação da MSE.

Algumas pesquisas $(n=3,10 \%)$ revelaram dificuldades no acompanhamento das famílias dos adolescentes. Familiares entrevistados em um estudo realizado no DF (Souza \& Costa, 2013) afirmaram desconhecer o que ocorria com os adolescentes durante o período de privação de liberdade. Acrescentaram que, embora soubessem da existência de reuniões de pais, não podiam comparecer por indisponibilidade de tempo ou por não se atentar às datas. Uma pesquisa realizada no RN (Medeiros \& Paiva, 2015) acompanhou familiares dos adolescentes e analisou documentos produzidos por técnicos. O trabalho revelou a insuficiência dos acompanhamentos familiares, que se resumiam a encaminhamentos a programas de renda ou de irmãos dos adolescentes a programas de aprendizagem técnica.

As práticas de escolarização são descritas por alguns estudos $(n=11,37 \%)$ como desinteressantes e ineficazes, aquém do objetivo de educar e transmitir conteúdos acadêmicos. Em três trabalhos (Menicucci \& Carneiro, 2011; Oliveira, 2003; Silva \& Ristum, 2010) discutiu-se que as unidades detinham tecnologias pouco efetivas para a participação dos adolescentes nas atividades escolares, sendo a punição pelas faltas recorrentemente apontada como única estratégia para incentivar a frequência e o bom comportamento escolar. Um desses estudos (Silva \& Ristum, 2010) revelou ainda que as atividades de escolarização sofriam forte interferência de procedimentos de segurança, sendo frequentemente canceladas em situações de revista dos alojamentos. Outra pesquisa (Padovani \& Ristum, 2013) teve por objetivo investigar a percepção de monitores sobre a atuação da escola de uma unidade quanto à prevenção e a diminuição da reincidência, tendo verificado a inefetividade de ações desse tipo.

As oficinas ocupacionais e/ou profissionalizantes foram descritas por algumas pesquisas $(n=7,23 \%)$ como precárias, por vezes ausentes, oferecidas, sobretudo, sem levar em consideração o interesse e a necessidade dos adolescentes. O estudo que comparou duas unidades em MG (Menicucci \& Carneiro, 2011) revelou que, em ambos os locais, os adolescentes apresentavam pouca autonomia quanto à participação nas oficinas. Em um dos estabelecimentos, a frequência era obrigatória; no outro, ainda que facultativa, a recusa em participar poderia gerar má avaliação semestral. O mesmo trabalho destacou, ainda, que as oficinas eram comprometidas devido à baixa escolaridade dos internos.

Elementos positivos sobre a escolarização e oficinas foram destacados em algumas pesquisas $(n=4,13 \%)$. Alguns adolescentes revelaram gostar da escola e das oficinas que frequentavam (Lazaretti-da-Conceição \& Cammarosano-Onofre, 2013; Muller et al., 2009). Outros adolescentes demonstraram satisfação com a forma de trabalho dos professores (Silva et al., 2013). Em uma unidade, verificou-se a tentativa de incentivar o envolvimento dos estudantes mediante oferta de aulas de reforço (Menicucci \& Carneiro, 2011).

Com relação às atividades de lazer e esporte, uma pesquisa realizada em SP (Lazaretti-da-Conceição \& Cammarosano-Onofre, 2013) teve por objetivo central compreender os processos educativos decorrentes do lazer para a educação de adolescentes em situação de privação de liberdade. Os adolescentes entrevistados conceberam como lazer os momentos de interação com outros adolescentes e funcionários. Essas atividades teriam por objetivo a vivência de manifestações da cultura corporal - prática de esportes, capoeira e hip hop - bem como a aprendizagem de novas habilidades - que os auxiliariam na superação da condição de privação de liberdade e na entrada no mercado de trabalho. O estudo indicou ainda que o exercício do lazer era limitado pela estrutura física e ausência de recursos na unidade.

A precariedade dos atendimentos em saúde foi mencionada por três pesquisas $(10 \%)$, destacando entre elas um trabalho sediado no DF (Vilarins, 2014), que tinha por objetivo analisar como são atendidos os adolescentes com transtorno mental. O estudo foi conduzido mediante entrevista com funcionários, registros em diário de campo e análise de prontuários, tendo constatado irregularidades na prestação do serviço. A maioria dos adolescentes com transtorno mental foi atendido pela psiquiatra da própria unidade ao invés de pela rede externa, conforme previsto por lei. Não obstante a terapia medicamentosa ter sido 
utilizada prevalentemente como método de tratamento, não havia registros de reavaliação da medicação, havendo casos de adolescentes consumindo a mesma prescrição por meses.

\section{Aspectos Interpessoais}

Compõem este tema os resultados das pesquisas que caracterizavam as relações interpessoais estabelecidas pelos adolescentes durante o período de cumprimento da MSE. Verificaram-se tanto elementos referentes às relações estabelecidas nas unidades quanto com familiares e amigos presentes durante o período de privação de liberdade.

Alguns trabalhos $(n=12,40 \%)$ descreveram o ambiente das unidades como marcado pela dificuldade e deterioração das relações interpessoais, permeadas por um clima de hostilidade, repressão, intriga e angústia que conduzia a inimizades e a conflitos entre adolescentes e entre estes e funcionários. Um estudo (Silva \& Ristum, 2010) realizado com professores de uma unidade, constatou que as relações estabelecidas pelos adolescentes entre si e com funcionários era mediada por uma tentativa de intimidação, que garantia a sobrevivência no ambiente. Uma pesquisa investigou a relação entre práticas e modelo pedagógico em uma unidade localizada no interior de Pernambuco (PE) (Monte \& Sampaio, 2012) por meio de entrevistas com adolescentes. Verificou-se que as relações estabelecidas com os monitores eram cerceadas pelo abuso de poder, punições expiatórias e pela compreensão de que estas se configuravam como atribuições legítimas desses funcionários. Um estudo sobre moralidade sediado no ES (Salgado \& Alencar, 2013) verificou a carência de relações cooperativas e a falta de integração de outras pessoas nos projetos pessoais dos adolescentes.

Elementos interpessoais positivos foram descritos em alguns trabalhos $(n=9,30 \%)$. A monitoria foi recordada por adolescentes de uma pesquisa conduzida no RS (Branco \& Wagner, 2009; Branco et al., 2008) como ocupando a função de regulação social, apoio emocional e conselheiro. Embora os monitores fossem indicados por adolescentes entrevistados em um estudo sediado na PB (Coutinho et al., 2011) como profissionais agressivos, os técnicos do local foram descritos como profissionais amigos. Em uma pesquisa conduzida com adolescentes de duas unidades também na PB (Estevam et al., 2009), os participantes de um dos locais consideraram a relação com os funcionários positiva, auxiliando-os na elaboração de seus projetos de vida.

Ainda que elementos interpessoais positivos sejam apontados, eles recorrentemente são descritos como pontuais, tratados como a exceção em um ambiente interpessoal predominantemente hostil. Um adolescente entrevistado no RJ (Oliveira, 2003) revelou que, durante o período de privação de liberdade, conheceu um monitor com quem estabeleceu uma relação positiva. Conforme relato do participante, após solicitação de sua chefia, o funcionário passou a adotar uma postura de distanciamento afetivo, o que despertou no adolescente angústia e solidão. Funcionários entrevistados em outra pesquisa também sediada no RJ (Oliveira \& Assis, 1999) apontaram o estabelecimento de relações pouco amistosas com os adolescentes, por vezes dificultadas pela provisoriedade da internação. Os funcionários afirmaram, entretanto, que, em meio às dificuldades, conquistavam a confiança de alguns adolescentes, transformando-se em referências positivas durante o cumprimento da MSE.

Foi indicado por alguns trabalhos $(n=6,20 \%)$ a formação de uma cultura endogrupal entre adolescentes em cumprimento de MSE. Uma pesquisa realizada no ES (Aragão et al., 2012) verificou que o convívio entre os adolescentes era marcado por um conjunto de normas não-escritas que preservava a coletividade em detrimento da individualidade. Três estudos (Estevam et al., 2009; Lazaretti-da-Conceição \& CammarosanoOnofre, 2013; Souza \& Costa, 2012a) revelaram a incorporação de gírias e códigos de valores e de conduta próprios das instituições de internação socioeducativa por parte dos adolescentes participantes. Outros dois trabalhos (Aragão et al., 2012; Scisleski et al., 2015) observaram que a alocação dos adolescentes em seus dormitórios variava conforme a política de afinidade entre os internos.

No que se refere às relações estabelecidas com familiares, algumas pesquisas $(n=6,20 \%)$ indicaram que, durante o período de cumprimento da MSE, os adolescentes passaram a dar maior importância à família. Ainda que admitissem que o período de internação fosse acompanhado por sofrimento, familiares entrevistados no interior do RS (Dias et al., 2011) afirmaram que a relação estabelecida com os adolescentes melhorou no transcurso da MSE, havendo reaproximação e maior vinculação afetiva entre eles. Adolescentes entrevistados no DF (Souza \& Costa, 2012b) indicaram que a família era a principal motivação para o cumprimento da MSE. Na mesma direção, um trabalho conduzido em Alagoas (AL) (Souza \& Menezes-Santos, 2010) observou, a partir de entrevistas com adolescentes, que o momento das visitas familiares eram sinalizados como os mais felizes durante a internação.

Aspectos negativos foram também observados acerca das relações com a família, seja no que se refere 
ao afastamento ou a ausência de vínculos $(n=5,17 \%)$ ou a violações de direitos durante as visitas familiares $(n=2,7 \%)$. Uma pesquisa conduzida no RJ (Oliveira \& Assis, 1999) constatou que $51 \%$ de seus participantes, em um universo de 537 adolescentes, não recebia visitas familiares. Em um estudo realizado a partir da observação participante de uma pesquisadora no DF (Souza \& Costa, 2012a) verificou-se que, nos dias dos pais, os adolescentes tinham a autorização de deixar a unidade na presença de um de seus responsáveis. A pesquisadora observou manifestações de retraimento e tristeza em adolescentes que não tiveram a presença dos familiares, tendo se recusado a participar das demais atividades. No que se refere às visitas familiares, pesquisas (Medeiros \& Paiva, 2015; Souza $\&$ Costa, 2013) indicaram procedimentos de revista vexatórios, mau tratamento por parte dos funcionários e demais situações descritas como humilhantes e desumanas.

De modo geral, o período de cumprimento da MSE caracteriza-se pelo enfraquecimento das relações interpessoais. Uma pesquisa realizada no RS (Branco \& Wagner, 2009) visava compreender o sucesso, ou não, da MSE à luz das características das redes sociais dos adolescentes e verificou, a partir de dois tempos de coleta de dados, uma diminuição destas ao longo da MSE. O estudo utilizou um instrumento que investigava pessoas presentes na rede social dos participantes em níveis distintos - família, amigos, escola, trabalho e comunidade - tendo observado maior concentração de membros nos quadrantes família e amigos. Nenhuma pessoa foi representada nos quadrantes escola e trabalho e, no segundo tempo de coleta de dados, houve diminuição geral dos membros representados, acentuando-se a concentração no quadrante família. No intervalo entre as coletas de dados, os participantes retomaram seu convívio com a comunidade a partir do cumprimento de MSE com possibilidade de saídas externas, esperando-se, portanto, que sua rede social aumentasse. O trabalho concluiu que o retorno à comunidade foi marcado pela dificuldade de articulação com a rede, bem como pela ruptura de um processo de idealização das relações estabelecidas com amigos e familiares, havendo um afastamento de pessoas que antes os participantes diziam confiar.

\section{Efeitos e Consequências}

Referem-se a este tema os resultados das pesquisas que caracterizam o impacto do cumprimento da MSE para os adolescentes em privação de liberdade. Nesse sentido, são abordados tanto os elementos presentes durante o período de internação quanto aqueles referentes ao momento posterior de retorno à comunidade e à família.

Algumas pesquisas caracterizaram o cumprimento da MSE como tendo efeitos negativos sobre a conduta infracional dos adolescentes, seja pelos altos índices de reincidência $(n=4,13 \%)$, seja como uma etapa de aprendizagem para o crime $(n=3,10 \%)$. A partir de entrevistas realizadas com adolescentes no interior do RS (Muller et al., 2009), foi observado que os participantes tendiam a compreender o aspecto retributivo da MSE, de modo a refletir sobre seus atos infracionais. Ainda assim, o trabalho constatou altos índices de reincidência entre os participantes, bem como a crença de que a desvinculação infracional se daria unicamente a partir de atributos e motivações pessoais dos adolescentes. Uma pesquisa documental retrospectiva (de abril de 1998 a dezembro de 2007) sediada no RS (Zappe \& Dias, 2011) observou que, de um universo de 736 adolescentes, 64\% deles haviam reingressado em instituições socioeducativas e 53\% ingressado no sistema prisional, havendo participantes pertencentes a ambos os grupos. Ainda que o reingresso no sistema socioeducativo pudesse se dar por meio do retorno após situação de fuga, o estudo concluiu que o sistema socioeducativo não se mostrava eficaz na elaboração de projetos de vida entre os adolescentes, que tendiam a permanecer em situação de conflito com a lei.

O processo de cumprimento da MSE resulta, segundo algumas pesquisas $(n=11,37 \%)$, em manifestações de discriminação e preconceito na comunidade, bem como a um processo de estigmatização que vincula os adolescentes a uma identidade infratora irreversível. Dois trabalhos (Dias et al., 2011; Muller et al., 2009) revelaram a crença de que o cumprimento da MSE pode significar dificuldades em se inserir no mercado de trabalho. Um estudo etnográfico (Malvasi, 2011) acompanhou um adolescente em SP na transição do cumprimento da MSE em meio fechado para o meio aberto. O trabalho observou que, quando do retorno à comunidade, as apreensões policiais feitas ao adolescente se intensificaram.

Um processo de perda da identidade pessoal também é descrito por alguns trabalhos $(n=9$, $30 \%$ ). O estudo etnográfico (Malvasi, 2011) acima mencionado identificou que o adolescente participante, durante o cumprimento da MSE, representou o bom comportamento esperado pelos técnicos e juízes como forma de obter sua liberdade. Essa mudança comportamental não foi interpretada pelo pesquisador, contudo, como uma falsificação de suas intenções, mas como uma introjeção dos elementos de submissão que o sistema reforçava. 
O período de cumprimento da MSE foi recorrentemente $(n=14,47 \%)$ caracterizado como uma experiência negativa, um inferno, marcado pelo sofrimento, ociosidade, tristeza, raiva, culpa, medo, apatia e pelo adoecimento, não só psicológico e moral, mas também físico. Um trabalho (Coutinho et al., 2011) que investigou as representações sociais de adolescentes sobre as práticas de privação de liberdade observou que os participantes ancoravam suas representações, dentre outros aspectos, em manifestações psicoafetivas caracterizadas por sentimentos de solidão e tristeza, bem como em manifestações físico-orgânicas de adoecimento - tais como alterações do sono, do apetite e das sensações corpóreas. Segundo uma pesquisa realizada no DF (Vilarins, 2014) sobre o atendimento oferecido a adolescentes com transtorno mental, a maioria dos diagnósticos psiquiátricos recebidos pelos adolescentes - insônia, ideação suicida, automutilação e depressão - associavam-se à experiência de sofrimento advinda do cumprimento da MSE.

Alguns estudos $(n=11,37 \%)$ descreveram a MSE, contudo, como uma experiência que propiciava proteção e aprendizagem. Uma pesquisa narrativa conduzida com um adolescente em AL (Souza \& Menezes-Santos, 2010) verificou que o participante revelou ter se arrependido do cometimento do ato infracional e construído novos caminhos a partir do cumprimento da MSE. Adolescentes entrevistados em um estudo realizado no interior do RS (Muller et al., 2009) identificaram a MSE como um meio de proteção contra riscos externos por seu histórico de envolvimento em atos infracionais. Uma pesquisa realizada no DF investigou o significado atribuído pelos adolescentes (Souza \& Costa, 2012b) e seus familiares (Souza \& Costa, 2013) à MSE de internação e outras cumpridas anteriormente. O trabalho verificou que a internação foi a única MSE que conseguiu garantir o mínimo preconizado pelo ECRIAD a partir da inserção dos adolescentes na escola e demais atividades pedagógicas. As demais MSE foram caracterizadas pela precariedade, ou mesmo ausência, do acompanhamento dos adolescentes.

\section{Considerações Finais}

A revisão sistemática permitiu verificar que o cumprimento da MSE de internação se diferencia muito da proposta socioeducativa da Doutrina da Proteção Integral. No que se refere ao contexto, prevaleceu a descrição de unidades afastadas dos centros urbanos, de estrutura física precarizada, marcada por um clima organizacional hostil e pela execução da MSE conforme lógica coercitiva. Com relação às atividades desenvolvidas nas unidades, observou-se a precarização dos atendimentos técnicos, acompanhamentos familiares, escolarização, profissionalização, atividades de lazer e esportes, e atendimentos em saúde. As relações interpessoais estabelecidas durante o tempo de privação de liberdade foram caracterizadas sobretudo enquanto hostis, havendo menção ainda a um conjunto de violações do direito de convivência familiar. Por fim, foram descritos efeitos e consequências negativos advindos do cumprimento da MSE, tais como reincidência, preconceito e estereótipo na comunidade, perda da identidade pessoal e sofrimento.

Elementos positivos do cumprimento da MSE foram também destacados pelas pesquisas, entretanto em menor frequência. A estrutura física de algumas unidades foram consideradas adequadas, por pesquisadores e participantes, havendo ainda a descrição de um clima organizacional livre de violência. Alguns adolescentes descrevem as atividades escolares e profissionalizantes como produtivas, destacando o interesse dos professores sobre os estudantes. O tempo de privação de liberdade propiciou a aproximação dos adolescentes com seus familiares, além de permitir a vinculação positiva dos adolescentes com alguns funcionários. Por fim, o tempo de cumprimento da MSE foi entendido por alguns adolescentes como favorecedor de aprendizagem e proteção.

Ainda que elementos positivos tenham sido apontados, os achados corroboram o relatório do Conselho Federal da Ordem dos Advogados do Brasil e Conselho Federal de Psicologia (2006), verificando-se que os princípios garantistas da Doutrina da Proteção Integral ainda configuram um processo em curso no âmbito de execução da MSE no País. Esforços devem ser reunidos no sentido de tornar esses princípios não apenas retóricos, mas também parte da realidade de prestação de serviços a este público. A ciência, que se manifesta por meio das atividades de pesquisa, tem papel fundamental neste processo, uma vez que lança luz sobre a realidade, podendo catalisar processos de mudanças.

A análise metodológica das pesquisas que compuseram este estudo observou, entretanto, que muitas carecem do rigor e sistematização que caracterizam uma investigação científica. Ainda que alguns trabalhos apresentassem rigorosa descrição dos procedimentos de coleta e análise de dados, em outros as considerações ao método foram escassas, o que diminuía sua qualidade metodológica. No que se refere a esses últimos, a redação dos resultados, recorrentemente, consistia em especulações teóricas que chegavam a conclusões semelhantes: a prevalência do caráter punitivo sobre o pedagógico no âmbito de execução das MSE, corroborando suas teorias. Enquanto se 
continuar produzindo trabalhos que cheguem às mesmas conclusões, a ciência pouco contribuirá para que a prática socioeducativa venha a se constituir, de fato, como congruente à Doutrina da Proteção Integral.

É preciso desenvolver pesquisas que investiguem o cotidiano das unidades, no sentido de extrair elementos que contribuam para as necessárias transformações na prática socioeducativa. Assim, os processos resultantes da situação de privação de liberdade devem ser alvo de análise, de modo a possibilitar o conhecimento válido para futuras intervenções que resultem na humanização e efetividade das MSE como catalisadoras de mudanças positivas. A prevalência do caráter punitivo sobre o socioeducativo na execução da MSE é algo amplamente sabido e a ciência, nesse sentido, pode contribuir de maneira mais efetiva se der subsídios sobre como inverter esta lógica, como promover o desenvolvimento saudável neste contexto, entre outras questões. Nessa direção, a prática científica deixa de ser apenas especulativa e torna-se também ética, comprometida não apenas com a produção do conhecimento, mas também com os processos de transformação social.

O trabalho apresenta, entretanto, limitações, uma vez que investigou apenas artigos empíricos indexados em quatro bases de dados. Resultados diferentes poderiam ser encontrados, se analisadas referências de outras fontes, tais como livros, teses e dissertações ou demais bases de dados. A estratégia de busca utilizada foi também limitadora, tendo em vista que não há na área uma linguagem controlada amplamente utilizada. Sugere-se que o termo Medida Socioeducativa seja adotado como linguagem controlada quando referidos trabalhos científicos sobre intervenções delegadas a adolescentes autores de ato infracional a partir de decisões judiciais. O termo é utilizado em legislações nacionais, como o ECRIAD e o SINASE, e deve ser adotado também nas produções científicas no País. Ademais, é importante destacar que não houve conflitos de interesse na redação do presente trabalho, tampouco os artigos analisados declararam conflitos de interesse que poderiam enviesar seus resultados.

\section{Referências}

Aragão, E. M. A., Margotto, L. R., \& Batista, R. (2012). Uma cidade-internação e suas multipli (cidades): encontros com adolescentes em cumprimento de medida socioeducativa. EPOS, 3(2), 1-21.

Aranzedo, A. C. \& Souza, L. D. (2007). Adolescentes autores de homicídio: vivência da privação de liberdade e planos para o futuro. Revista electrónica de psicología política, 5(15).

Branco, B. M., Wagner, A., \& Demarchi, K. A. (2008). Adolescentes infratores: rede social e funcionamento familiar. Psicologia: Reflexão e Crítica, 21(1), 125-132. https://doi.org/10.1590/S0102-79722008000100016

Branco, B. M. \& Wagner, A. (2009). Os adolescentes infratores e o empobrecimento da rede social quando do retorno à comunidade. Ciência \& Saúde Coletiva, 14(2), 557-566. https://doi.org/10.1590/S1413-81232009000200024

Brasil. (1990, 16 de julho). Lei no 8.069, de 13 de julho de 1990. Estatuto da Criança e do Adolescente. Diário Oficial da União, p. 13.563.

Brasil. (2006). Conselho Nacional dos Direitos da Criança e do Adolescente. Sistema Nacional de Atendimento Socioeducativo - SINASE. Brasília-DF: CONANDA.

Brasil. (2012, 19 de janeiro). Lei no 12.594, de 18 de janeiro de 2012. Sistema Nacional de Atendimento Socioeducativo (Sinase). Diário Oficial da União, p. 3.

Braun, V. \& Clarke, V. (2006). Using thematic analysis in psychology. Qualitative Research in Pshychology, 3, 77-101. https://doi.org/10.1191/1478088706qp063oa

Castro, A. L. S. \& Guareschi, P. (2008). Da privação da dignidade social à privação da liberdade individual. Psicologia \& Sociedade, 20(2), 200-207. https://doi.org/10.1590/S0102-71822008000200007

Conselho Federal da Ordem dos Advogados do Brasil \& Conselho Federal de Psicologia (2006). Um retrato das unidades de internação de adolescentes em conflito com a lei (2 ${ }^{\underline{a}}$ ed.). Brasília: Autores.

Coutinho, M. D. P. L., Estevam, I. D., de Araújo, L. F., \& Araújo, L. S. (2011). Prática de privação de liberdade em adolescentes: um enfoque psicossociológico. Psicologia em Estudo, 16(1), 101-109. https://doi.org/10.1590/S141373722011000100012

Dias, A. C. G., Arpini, D. M., \& Simon, B. R. (2011). Um olhar sobre a família de jovens que cumprem medidas socioeducativas. Psicologia \& Sociedade, 23(3), 526-535. https://doi.org/10.1590/S0102-71822011000300010

Estevam, I. D., Coutinho, M. D. P. L., \& Araújo, L. F. (2009). Os desafios da prática socioeducativa de privação de liberdade em adolescentes em conflito com a lei: ressocialização ou exclusão social? Psico, 40(1), 64-72.

Ferrão, I. S., Zappe, J. G., \& Dias, A. C. G. (2012). O olhar de socioeducadores de uma unidade de internação sobre a efetivação da doutrina da proteção integral. Barbarói, (36), 42-55.

Galvão, L., Costa, J. B. D., \& Camino, C. (2005). Conhecimento dos Direitos Humanos por adolescentes privados de liberdade: um estudo comparativo de duas instituições. Psico, 36(3), 275-282. 
Lazaretti-da-Conceição, W., \& Cammarosano-Onofre, E. M. (2013). Adolescentes em privação de liberdade: as práticas de lazer e seus processos educativos. Revista Latinoamericana de Ciencias Sociales, Niñez y Juventud, 11(2), 573-585. https://doi.org/10.11600/1692715x.1128120912

Lima, R. D. C. P. (2006). Mudança das práticas socioeducativas na FEBEM-SP: As representações sociais de funcionários. Psicologia \& Sociedade, 18(1), 56-62. https://doi.org/10.1590/S0102-71822006000100008

Malvasi, P. A. (2011). Entre a frieza, o cálculo e a "vida loka": violência e sofrimento no trajeto de um adolescente em cumprimento de medida socioeducativa. Saúde \& Sociedade, 20(1), 156-170. https://doi.org/10.1590/S010412902011000100018

Medeiros, F. C. \& de Paiva, I. L. (2015). A convivência familiar no processo socioeducativo de adolescentes em privação de liberdade. Estudos e Pesquisas em Psicologia, 15(2),568-586. https://doi.org/10.12957/epp.2015.17659

Menicucci, C. G. \& Carneiro, C. B. L. (2011). Entre monstros e vítimas: a coerção e a socialização no sistema socioeducativo de Minas Gerais. Serviço Social \& Sociedade, (107), 535-536. https://doi.org/10.1590/S0101-66282011000300009

Monte, F. F. C. \& Sampaio, L. R. (2012). Práticas pedagógicas e moralidade em unidade de internamento de adolescentes autores de atos infracionais. Psicologia: Reflexão e Crítica, 25(2), 368-377. https://doi.org/10.1590/S010279722012000200019

Muller, F., Barboza, P. D. S., Oliveira, C. C. D., Santos, R. R. G. D., \& Paludo, S. D. S. (2009). Perspectivas de adolescentes em conflito com a lei sobre o delito, a medida de internação e as expectativas futuras. Revista Brasileira Adolescência e Conflitualidade, 1(1), 70-87.

Padovani, A. S. \& Ristum, M. (2013). A escola como caminho socioeducativo para adolescentes privados de liberdade. Educação e Pesquisa, 39(4), 969-984. https://doi.org/10.1590/S1517-97022013005000012

Oliveira, E. R. (2003). Ensinando a não sonhar: a anti-pedagogia oficial destinada a adolescentes infratores no estado do Rio de Janeiro. Revista Katálysis, 6(1), 85-95.

Oliveira, M. B. \& Assis, S. G. (1999). Os adolescentes infratores do Rio de Janeiro e as instituições que os "ressocializam" - A perpetuação do descaso. Cadernos de Saúde Pública, 15(4), 831-844. https://doi.org/10.1590/ S0102-311X1999000400017

Rizzini, I. \& F. Pilotti, F. (2011). A arte de governar crianças: a história das políticas sociais, da legislação e da assistência à infância no Brasil (2ª ed.). São Paulo: Cortez.

Salgado, M. M. \& Alencar, H. M. D. (2013). Caracterização de adolescentes em medida de internação: Estudo na área da moralidade. Psicologia Argumento, 31(73), 257-269.

Scisleski, A. C. C., Bruno, B. S., Galeano, G. B., Santos, S. N. D., \& Silva, J. L. C. D. (2015). Medida socioeducativa de internação: estratégia punitiva ou protetiva?. Psicologia \& Sociedade, 27(3), 505-515. https://doi.org/10.1590/180703102015v27n3p505

Silva, D. C. D. O., Ruzzi-Pereira, A., \& Pereira, P. E. (2013). Fatores protetivos à reincidência ao ato infracional? concepções de adolescentes em privação de liberdade. Caderno de Terapia Ocupacional, 21(03), 553-561. https:// doi.org/10.4322/cto.2013.057

Silva, J. O. \& Ristum, M. (2010). A violência escolar no contexto de privação de liberdade. Psicologia: Ciência e Profissão, 30(2), 232-247. http://dx.doi.org/10.1590/s141498932010000200002

Souza, L. A. \& Costa, L. F. (2012a). Aspectos institucionais na execução da medida socioeducativa de internação. Revista Psicologia Politica, 12(24), 231-245. https://doi.org/10.1590/S1413-82712013000200011

Souza, L. A. \& Costa, L. F. (2012). O Significado de medidas socioeducativas para adolescentes privados de liberdade. Acta Colombiana de Psicología, 15(2), 87-97.

Souza, L. A. D., \& Costa, L. F. (2013). A significação das medidas socioeducativas para as famílias de adolescentes privados de liberdade. Psico USF, 18(2), 277-287. https://doi.org/10.1590/S1413-82712013000200011

Souza, M. M. S., \& Menezes-Santos, J. A. (2010). O processo de desvinculação de um adolescente com a prática infracional, a partir do cumprimento de medida socioeducativa privativa de liberdade. Pesquisas e Práticas Psicossociais, 5(2).

Vilarins, N. P. G. (2014). Adolescentes com transtorno mental em cumprimento de medida socioeducativa de internação. Ciência \& Saúde Coletiva, 19(3), 891-898. https://doi.org/10.1590/1413-81232014193.13042013

Zappe, J. G. \& Dias, A. C. G. (2011). Grades não prendem pensamentos: limites da institucionalização na reconstrução do projeto de vida do adolescente. Psico, 42(2), 220-227.

\footnotetext{
Autores:

Vinicius Coscioni - Mestre, Universidade Federal do Espírito Santo. Doutorando, Universidade Federal do Rio Grande do Sul.

Luiza Lins Araújo Costa - Mestre, Universidade Federal de Sergipe.

Edinete Maria Rosa - Doutora, Universidade Federal do Espírito Santo.

Sílvia Helena Koller - Doutora, Universidade Federal do Rio Grande do Sul.

Endereço para correspondência:

Vinicius Coscioni

Rua Luiz Afonso, 395/302 - Cidade Baixa

90050-310 - Porto Alegre, RS, Brasil

$<$ viniciuscoscioni@gmail.com>

Recebido em: 15.08 .2016

Aceito em: 23.03.2017
} 